See Article page 1438.

\section{Commentary: Potts shunt for pulmonary hypertension: Are we making progress?}

\author{
Jacob R. Miller, MD, and Pirooz Eghtesady, MD, PhD
}

Recently, the Potts shunt has emerged as an option for pulmonary arterial hypertension with the aim of delaying lung transplantation. ${ }^{1,2}$ In this issue of the Journal, Rosenzweig and colleagues $^{3}$ take us one step further, reporting their initial excellent experience in 5 adolescents using a valved shunt. They used their previously described unidirectional-valved shunt (UVS) from the main pulmonary artery (MPA) to the aorta with a Contegra conduit (Medtronic, Minneapolis, Minn) embedded in a PTFE tube graft. ${ }^{4}$ Although in principle, with suprasystemic right-sided pressures, the shunt should be exclusively right to left, clinical observations have shown otherwise; Figure 1, A, shows simultaneous opacification of the aorta and the left pulmonary artery. This potential is well illustrated by Rosenzweig and colleagues in their Figure E1.

Compared with a Potts shunt with a direct anastomosis performed via thoracotomy, this operation performed via sternotomy should protect against any left-to-right shunting. It also should reduce the risk of left chest adhesions, which can be treacherous at the time of transplantation, based on our limited first-hand experience. In addition, we believe that placing the conduit on the MPA allows for more uniform RV decompression, particularly given the often-discrepant branch PA sizes. Furthermore, as we have become more aggressive at concomitantly addressing any residual right-sided lesions, such as pulmonary/ tricuspid insufficiency or atrial septal defect (the latter surprisingly often showing mainly left-to-right shunting), we have found an anterior approach to be quite helpful. Finally,

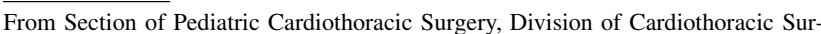
gery, Department of Surgery, Washington University in St Louis School of Medicine/St Louis Children's Hospital, St Louis, Mo.

Disclosures: The authors reported no conflicts of interest.

The Journal policy requires editors and reviewers to disclose conflicts of interest and to decline handling or reviewing manuscripts for which they may have a conflict of interest. The editors and reviewers of this article have no conflicts of interest.

Received for publication Jan 4, 2021; revisions received Jan 4, 2021; accepted for publication Jan 5, 2021; available ahead of print January 28, 2021.

Address for reprints: Pirooz Eghtesady, MD, PhD, Section of Pediatric Cardiothoracic Surgery, Division of Cardiothoracic Surgery, Department of Surgery, St Louis Children's Hospital, One Children's Place, Suite 5 South, St Louis, MO 63110 (E-mail: eghtesadyp@wudosis.wustl.edu).

J Thorac Cardiovasc Surg 2021;161:1449-50

$0022-5223 / \$ 36.00$

Copyright (c) 2021 by The American Association for Thoracic Surgery

https://doi.org/10.1016/j.jtcvs.2021.01.003
}

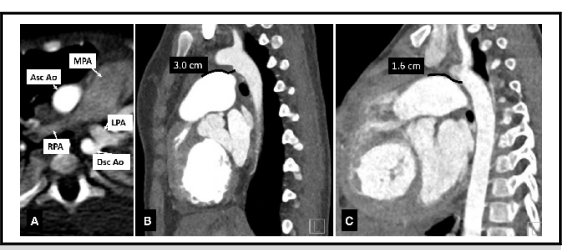

A, Computed tomography angiogram after the Potts shunt procedure. B and C, Aortopulmonary window in an adolescent (B) and in a child (C), with a valved and a nonvalved conduit, respectively.

\section{CENTRAL MESSAGE \\ The unidirectional valved shunt is a new option for selected pa- tients with idiopathic pulmonary arterial hypertension that may overcome some limitations of previous techniques. Optimal patient selection and timing are crucial but remain unclear.}

we have found the valved conduit also to be useful for patients with systemic PA pressures who become suprasystemic only with exercise.

There are differences in this series from our experience to date ( 5 patients, age range 7 to 22 years). None of the patients in the current report had resting oxygen requirements, and venovenous extracorporeal membrane oxygenation was used postoperatively in 4 patients (none in our experience). Finally, the authors used warfarin postoperatively. This may be reasonable, given the deep sinuses of the Contegra conduit; however, we find the antiplatelet effect of prostacyclins and observed high flow through the conduit to be sufficient.

Despite its advantages, the valved conduit has some limitations. It lacks growth potential, the length of the valve requires a reasonable aortopulmonary window (minimum $\sim 2.5 \mathrm{~cm}$ ) to ensure the conduit is not kinked (Figure 1, $B$ and $C$ ), and it has similar durability concerns as other biological conduits. To overcome these limitations, in our practice, if the aortopulmonary window is too short, we use a $10-\mathrm{mm}$ nonvalved conduit, because these can later be dilated up to 2 sizes and accept a transcatheter valve. For the youngest patients, we still prefer the thoracotomy approach to preserve growth potential.

We still do not know whether the Potts shunt will alter the long-term prognosis of these children. Our preliminary experiences suggest similar, and possibly even superior, outcomes compared with transplantation. ${ }^{5}$ Hopefully, with 

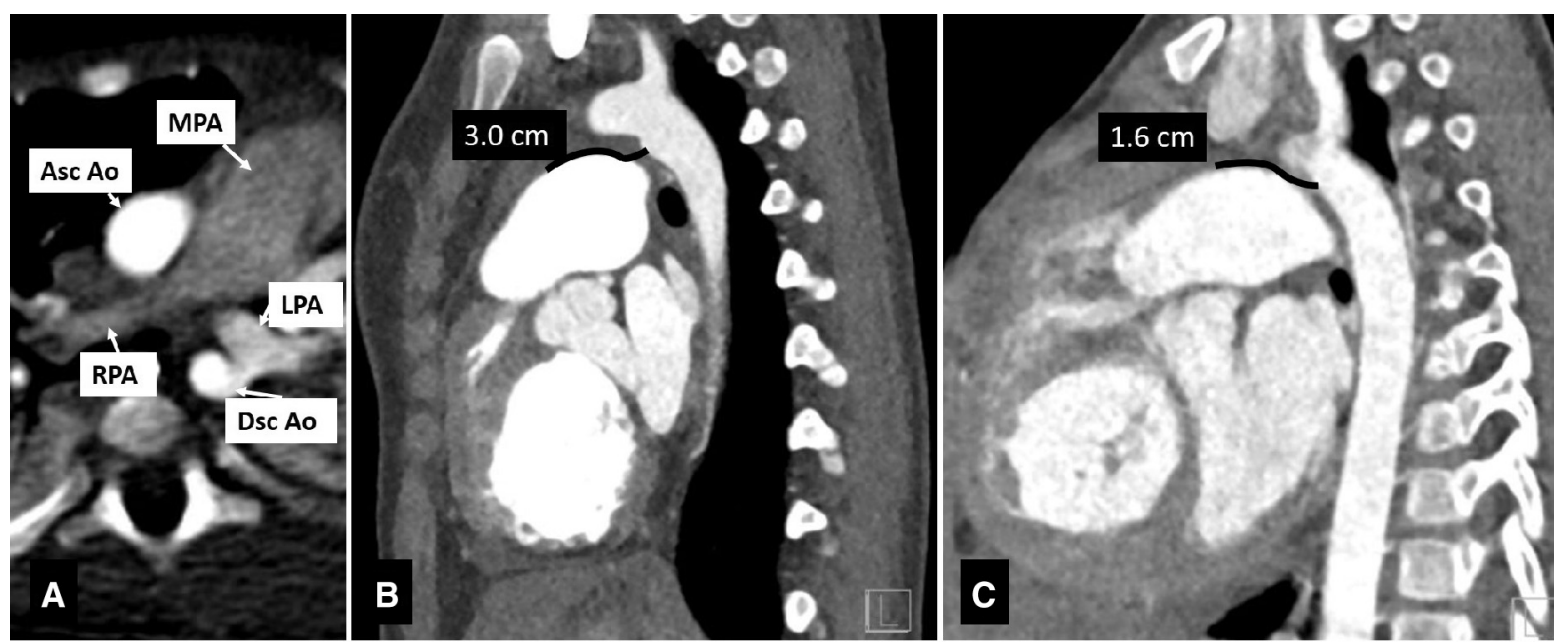

FIGURE 1. A, Computed tomography angiogram after the Potts shunt procedure. B and C, Aortopulmonary window in an adolescent (B) and in a child (C), with a valved and a nonvalved conduit, respectively.

time, these technical modifications will translate into better outcomes.

\section{References}

1. Baruteau AE, Serraf A, Lévy M, Petit J, Bonnet D, Jais X, et al. Potts shunt in children with idiopathic pulmonary arterial hypertension: long-term results. Ann Thorac Surg. 2012;94:817-24.

2. Grady RM, Eghtesady P. Potts shunt and pediatric pulmonary hypertension: what we have learned. Ann Thorac Surg. 2016;101:1539-43.
3. Rosenzweig EB, Ankola A, Krishnan U, Middlesworth W, Bacha E, Bacchetta M A novel unidirectional-valved shunt approach for end-stage pulmonary arterial hypertension: early experience in adolescents and adults. J Thorac Cardiovasc Surg. 2021;161:1438-46.e2

4. Salna M, van Boxtel B, Rosenzweig EB, Bacchetta M. Modified Potts shunt in an adult with idiopathic pulmonary arterial hypertension. Ann Am Thorac Soc. 2017; 14:607-9.

5. Lancaster TS, Shahanavaz S, Balzer DT, Sweet ST, Grady RM, Eghtesady P. Midterm outcomes of the Potts shunt for pediatric pulmonary hypertension, with comparison to lung transplant. J Thorac Cardiovasc Surg. 2021;161:1139-48. 